\title{
Anemia and blood transfusion in a surgical intensive care unit
}

\author{
Yasser Sakr*1, Suzana Lobo', Stefanie Knuepfer ${ }^{1}$, Elizabeth Esser ${ }^{1}$, Michael Bauer ${ }^{1}$, Utz Settmacher², Dagmar Barz ${ }^{3}$ and \\ Konrad Reinhart ${ }^{1}$
}

\begin{abstract}
Introduction: Studies in intensive care unit (ICU) patients have suggested that anemia and blood transfusions can influence outcomes, but these effects have not been widely investigated specifically in surgical ICU patients.

Methods: We retrospectively analyzed the prospectively collected data from all adult patients ( $>18$ years old) admitted to a 50-bed surgical ICU between 15t March 2004 and 30th July 2006.

Results: Of the 5925 patients admitted during the study period, 1833 (30.9\%) received a blood transfusion in the ICU. Hemoglobin concentrations were $<9 \mathrm{~g} / \mathrm{dl}$ on at least one occasion in $57.6 \%$ of patients. Lower hemoglobin concentrations were associated with a higher Simplified Acute Physiology Score II and Sequential Organ Failure Assessment score, greater mortality rates, and longer ICU and hospital lengths of stay. Transfused patients had higher ICU (12.5 vs. 3.2\%) and hospital (18.3 vs. $6.5 \%)$ mortality rates (both $p<0.001)$ than non-transfused patients. However, ICU and in-hospital mortality rates were similar among transfused and non-transfused matched pairs according to a propensity score ( $n=1184$ pairs), and after adjustment for possible confounders in a multivariable analysis, higher hemoglobin concentrations (RR 0.97[0.95-0.98], per $1 \mathrm{~g} / \mathrm{dl}, \mathrm{p}<0.001$ ) and blood transfusions (RR 0.96[0.92-0.99], $\mathrm{p}=$ 0.031) were independently associated with a lower risk of in-hospital death, especially in patients aged from 66 to 80 years, in patients admitted to the ICU after non-cardiovascular surgery, in patients with higher severity scores, and in patients with severe sepsis.

Conclusions: In this group of surgical ICU patients, anemia was common and was associated with higher morbidity and mortality. Higher hemoglobin concentrations and receipt of a blood transfusion were independently associated with a lower risk of in-hospital death. Randomized control studies are warranted to confirm the potential benefit of blood transfusions in these subpopulations.
\end{abstract}

\section{Introduction}

Anemia is common in critically ill patients [1-4] and is associated with considerable morbidity and worse outcome [1,3]. Conversely, several studies $[1,3]$ have indicated a potential association between blood transfusion and poor outcome from critical illness. Large observational European [1] and North American [3] cohort studies on blood transfusion practices in critically ill patients reported that blood transfusion was independently associated with an increased risk of death. This association was confirmed in propensity score-matched groups. Studies in trauma patients [5], in patients with burns [6],

* Correspondence: Yasser.Sakr@med.uni-jena.de

1 Department of Anesthesiology and Intensive Care, Friedrich Schiller University Hospital, Erlanger Allee 103, Jena, 07743, Germany Full list of author information is available at the end of the article in patients undergoing cardiac surgery [7], and in patients with acute coronary syndromes [8] have also suggested increased mortality rates associated with blood transfusions.

A landmark study by Hébert and colleagues [9], the transfusion requirements in critically ill patients (TRICC) study, demonstrated that a restrictive strategy of red blood cell (RBC) transfusion was as effective as a liberal strategy. Moreover, these authors [9] reported a survival benefit with the restrictive strategy in patients younger than 55 years and those with acute physiology and chronic health evaluation (APACHE) II scores of 20 or less. Similarly, in a recent study in pediatric critically ill patients, Lacroix and colleagues [10] reported that restricting transfusions to patients with a hemoglobin 
threshold of $7 \mathrm{~g} / \mathrm{dl}$ was not associated with an increase in adverse events compared with patients transfused according to a trigger of $9.5 \mathrm{~g} / \mathrm{dl}$.

Heightened awareness of the possible risks of blood transfusion has led to changes in blood preparation so that blood transfusions may be safer today than they were a decade ago, not only in terms of viral transmission $[11,12]$, but also in terms of transfusion related immunosuppression (TRIM) [12-14]. In particular, leukoreduction, which may reduce some of the negative immunosuppressive effects of transfusions, has been widely implemented $[12,15,16]$. A recent observational study [2], the sepsis occurrence in acutely ill patients (SOAP) study, showed that in 821 pairs of patients matched according to a propensity score, the 30-day survival rate was higher in the transfusion group than in patients who were not transfused. The effects of blood transfusion need, therefore, to be reassessed following these changes in transfusion preparation and practice.

The aim of our study was to investigate the epidemiology and associated outcome of anemia and blood transfusion in a large cohort of surgical ICU patients.

\section{Materials and methods}

The study was approved by the institutional review board of Friedrich Schiller University Hospital, Jena, Germany. Informed consent was waived due to the retrospective, anonymous nature of the analysis. We retrospectively included all adult ( $>18$ years old) patients admitted to our 50-bed surgical ICU between 1 March 2004 and 30 July 2006. For patients admitted more than once to the ICU only the first admission was considered.

\section{Data collection}

Data were collected from vital sign monitors, ventilators and infusion pumps, and automatically recorded by a clinical information system (Copra System GmbH, Sasbachwalden, Germany). The clinical information system provides staff with complete electronic documentation, order entry (e.g., medications), and direct access to laboratory results. Data recorded prospectively on admission included age, gender, referring facility, primary and secondary admission diagnoses, and surgical procedures. Admission diagnosis was categorized retrospectively on the basis of prospectively recorded codes from the International Classification of Diseases-10 and electronic patient charts.

The simplified acute physiology score (SAPS) II [17] was calculated on admission and the sequential organ failure assessment (SOFA) score [18] calculated daily by the physician in charge of the patient using a special sheet. A plausibility check of the automatically transmitted data was performed by the attending physician before calculating the final scores. In sedated patients, Glasgow
Coma Scale prior to initiation of sedation was considered. Hospital mortality and hospital discharge dates were available for all patients from the electronic hospital records.

Blood transfusion was registered electronically in the clinical information system as part of standard procedure in our ICU. Each blood transfusion unit was recorded separately using identification codes that allow tracing in case of suspected or confirmed adverse events. According to our local standards, hemoglobin concentrations should be kept above $7 \mathrm{~g} / \mathrm{dl}$ in all patients unless blood transfusion is explicitly refused by patients or their next of kin. Hemoglobin concentrations are targeted between 7 to 9 $\mathrm{g} / \mathrm{dl}$ by administration of one unit of blood at a time followed by determination of hemoglobin concentration. The attending physician may decide to target hemoglobin concentrations above $9 \mathrm{~g} / \mathrm{dl}$ in the presence of multiple comorbidities, ischemic heart disease, cardiovascular instability, or evidence of tissue hypoperfusion such as increased blood lactate levels or decreased central or mixed venous oxygen saturation. Blood transfusion is discouraged when hemoglobin concentrations are above 10 g/dl. Pre-storage leukodepletion was performed as a standard procedure. Regular quality control checks are performed by the transfusion authorities in our hospital and regular training is given by special personnel.

\section{Definitions}

Comorbidities were defined according to the definitions provided in the original SAPS II paper [17]. SOFAmax was defined as the maximum SOFA score recorded during the ICU stay and SOFAmean as the mean value during the ICU stay [18]. Sepsis syndromes were defined according to consensus conference definitions [19] and their presence was recorded daily by the attending physician in a specific section of the electronic records. Planned admission was defined as an admission after elective surgery that was planned 24 hours before the surgical procedure was conducted.

\section{Subgroup analysis}

A priori subgroups were defined arbitrarily according to admission characteristics and included age (18 to 50 years, 51 to 65 years, 66 to 80 years, and more than 80 years), SAPS II score $(<24,25$ to 50,51 to 75 , and more than 75 ), SOFA score ( 0 to 4,5 to 8,9 to 12 , and more than 12), surgical procedures (cardiovascular vs. non-cardiovascular surgery), and the occurrence of severe sepsis.

\section{Statistical analysis}

Data were analyzed using SPSS 13.0 for windows (SPSS Inc, Chicago, IL, USA) and SAS version 9.1.3 software (SAS Institute Inc., Cary, NC, USA). Difference testing between groups was performed using a Wilcoxon test, Mann-Whitney U test, chi-square test and Fisher's exact 
test as appropriate. A Bonferroni correction was used for multiple comparisons. Analysis of variance was used to assess progression of SOFA score within and among subgroups.

To determine the relative risk of hospital death we developed a multivariable Cox proportional hazard model in the overall population. Variables considered for the Cox regression analysis included age, gender, mechanical ventilation, hemofiltration, referring facility, comorbid diseases, SAPS II and SOFA scores and SOFA subscores on admission, the type of admission (planned or unplanned), the type of surgery, the presence of sepsis during the ICU stay, hemoglobin concentration on admission to the ICU, the minimum hemoglobin concentration during ICU stay, the number of transfused blood units in the ICU, and the maximum number of transfused units within 24 hours during the ICU stay. Colinearity between variables was excluded before modeling. Variables were introduced into this model if significantly associated with a higher risk of in-hospital death on a univariate basis at a $P$ less than 0.2 or if clinically relevant variables. To avoid bias related to longer ICU stay in transfused patients, we adjusted for the ICU length of stay (in non-transfused patients) and the time to the first transfusion (in transfused patients). Blood transfusion was introduced in the final model as a time-dependent variable. Another similar Cox regression analysis was performed to evaluate the effects of blood transfusion on in-hospital mortality in subgroups of patients according to gender, age, type of surgery, presence of severe sepsis, and for the different strata of the severity scores.

Propensity scores [20] were obtained through logistic regression of patient characteristics on blood transfusion status, that is, need for blood transfusion as the dependent factor. The propensity score was calculated as the probability based on the final model. A greedy matching technique was used to match individual patients who received a blood transfusion at any time with individual patients who did not, based on propensity scores. The best-matched propensity score was five digits long. Once a match was made, the control patient was removed from the pool. This process was then repeated using four-digit matching, then three-digit matching, and so on. The process proceeded sequentially to a single-digit match on propensity score. If a match was not obtained at this point, the patient who had received a blood transfusion was excluded.

All statistics were two-tailed, and a $P$ less than 0.05 was considered to be significant. Continuous variables are presented as mean \pm standard deviation or median (25 to $75 \%$ interquartile range (IQR)) and categorical variables as number and percentage, unless otherwise indicated.

\section{Results}

A total of 5,925 patients were admitted to our ICU during the study period. The characteristics of the study group are presented in Table 1.

\section{Hemoglobin concentrations and outcome}

On ICU admission, hemoglobin concentrations were less than $7 \mathrm{~g} / \mathrm{dl}$ in $18.7 \%$ of patients and between 7 and $9 \mathrm{~g} / \mathrm{dl}$ in $29.5 \%$ of patients (mean $9.9 \mathrm{~g} / \mathrm{dl}$ ). During the ICU stay, hemoglobin concentrations were less than $9 \mathrm{~g} / \mathrm{dl}$ on at least one occasion in $57.6 \%$ of patients. Mean hemoglobin concentrations decreased or increased towards median levels of $10 \mathrm{~g} / \mathrm{dl}$ throughout the first two weeks in the ICU (Figure 1). Patients with hemoglobin concentrations less than $9 \mathrm{~g} / \mathrm{dl}$ on admission to the ICU had higher SAPS II and SOFA scores than those with higher hemoglobin concentrations [see Table S1 in Additional file 1]. ICU and hospital mortality rates were higher and ICU and hospital lengths of stay were longer in patients with lower hemoglobin concentrations (Table 2). In patients discharged from the ICU $(n=5,564)$, in-hospital mortality rates were lower in those with higher hemoglobin concentrations on ICU discharge ( $<7,7$ to $9,9.1$ to $11,>11 \mathrm{~g} /$ dl; 7.3, 7.8, 4.0, and 3.8\%, respectively, $P<0.001$ ) than those with lower haemoglobin concentrations. SOFA scores increased during the first week in the ICU in all patients [see Figure S1 in Additional file 1]. Patients with hemoglobin concentrations of more than $11 \mathrm{~g} / \mathrm{dl}$ had the lowest SOFA scores during the first week in the ICU.

\section{Blood transfusion}

A total of 1,833 patients (30.9\%) received a blood transfusion in the ICU within a median of 1 (IQR 1 to 2 ) days. The initial blood transfusion was given on the first day in the ICU in $69 \%$ of transfused patients $(n=1,209)$. Transfused patients were older, were more commonly unplanned admissions, had greater SAPS II and SOFA scores, and had a higher incidence of comorbid conditions than patients who were not transfused [see Table S2 in Additional file 1]. The mean hemoglobin concentration prior to transfusion was $8.2 \pm 1.4 \mathrm{~g} / \mathrm{dl}(24 \%$ at $<7 \mathrm{~g} /$ dl, $46.6 \%$ at 7 to $9 \mathrm{~g} / \mathrm{dl}, 29.4 \%$ at $>9 \mathrm{~g} / \mathrm{dl}$ ). Characteristics of patients according to the number of transfused units are presented in Table S3 in Additional file 1.

Transfused patients had higher ICU and in-hospital mortality rates (12.5 vs. 3.2 and 18.3 vs. $6.5 \%$, respectively, both $P<0.001$ pairwise) and longer ICU and hospital lengths of stay (4 (2 to 11 ) vs. 1 ( 1 to 2 ) and 15 (11 to 26 ) vs. 11 ( 8 to 16 ) days, respectively, both $P<0.001$ pairwise) than non-transfused patients. There was a relation between the number of transfused units of blood and the degree of organ dysfunction/failure during the ICU stay, as assessed by SOFA scores, length of stay in the ICU, and mortality rates (Table 3 ). About $50 \%$ of patients who 
Table 1: Characteristics of the study group on admission to the ICU

\begin{tabular}{|c|c|}
\hline & All patients \\
\hline $\mathrm{N}$ & 5,925 \\
\hline Age, years, mean $\pm S D$ & $62.2 \pm 15.2$ \\
\hline Gender, male (\%) & $3,748(63.3)$ \\
\hline \multicolumn{2}{|l|}{ Referring facility } \\
\hline Operating/recovery room & $4,482(75.7)$ \\
\hline Emergency room & $393(6.6)$ \\
\hline Other hospital & $30(0.5)$ \\
\hline Other ICU & $455(7.6)$ \\
\hline Others & $565(9.6)$ \\
\hline \multicolumn{2}{|l|}{ Comorbidities (\%) } \\
\hline Diabetes mellitus & $1,316(22.2)$ \\
\hline Cancer & $1,234(20.8)$ \\
\hline Chronic renal failure & 700 (11.9) \\
\hline COPD & $143(2.4)$ \\
\hline Cirrhosis & $133(2.2)$ \\
\hline Heart failure (NYHA III to IV) & $75(1.3)$ \\
\hline Hematologic cancer & $8(0.1)$ \\
\hline Mechanical ventilation (\%) & $3,248(54.8)$ \\
\hline \multicolumn{2}{|l|}{ Severity scores, mean \pm SD } \\
\hline SAPS II score & $36.7 \pm 18.2$ \\
\hline SOFA score & $5.9 \pm 3.9$ \\
\hline \multicolumn{2}{|l|}{ Surgery within 24 hours } \\
\hline Cardiovascular surgery & $2,210(37.3)$ \\
\hline General surgery & $1,130(19.1)$ \\
\hline Neurosurgery & $831(14.0)$ \\
\hline Trauma & $342(5.8)$ \\
\hline Thoracic surgery & $260(4.4)$ \\
\hline Others & $1,152(19.4)$ \\
\hline Unplanned admissions (\%) & $1,495(25.2)$ \\
\hline Hemoglobin concentration, $\mathrm{g} / \mathrm{dl}$, mean $\pm \mathrm{SD}$ & $9.9 \pm 2.3$ \\
\hline ICU mortality rate (\%) & $361(6.1)$ \\
\hline Hospital mortality rate (\%) & $601(10.1)$ \\
\hline ICU LOS, days, median (IQR) & $1(1-4)$ \\
\hline Hospital LOS, days, median (IQR) & $12(9-19)$ \\
\hline \multicolumn{2}{|c|}{$\begin{array}{l}\text { COPD: chronic obstructive pulmonary disease; IQR: interquartile } \\
\text { range; LOS: length of stay; NYHA: New York Heart Association; } \\
\text { SAPS: simplified acute physiology score; SD: standard deviation; } \\
\text { SOFA: sequential organ failure assessment. }\end{array}$} \\
\hline
\end{tabular}

received more than eight units of blood died in the hospital. Patients who were transfused later in the ICU stay had higher mortality rates than those who were transfused earlier during the ICU stay (see Figure S2 in the Additional file 1).

\section{Multivariable adjustment}

In the multivariable Cox regression analysis with in-hospital death as the dependent variable, higher hemoglobin concentrations (relative risk $(\mathrm{RR})=0.97,95 \%$ confidence interval $(\mathrm{CI})=0.95$ to 0.98 , per $1 \mathrm{~g} / \mathrm{dl}, P \leq 0.001)$ and receipt of a blood transfusion $(\mathrm{RR}=0.96,95 \% \mathrm{CI}=0.92$ to $0.99, P=0.031)$ were independently associated with a lower risk of in-hospital death [see Table S4 in Additional file 1].

\section{Propensity score matching}

A total of 1,184 pairs were matched according to their propensity score [see Table S5 and Figure S3 in Additional file 1]. Transfused patients for whom propensity score-matched pairs were found had a higher incidence of chronic renal failure and cirrhosis, were more commonly unplanned admissions, had greater SAPS II and SOFA scores and lower hemoglobin concentrations on admission to the ICU, had higher mortality rates, and longer ICU and hospital lengths of stay than those for whom no matched pairs were found $(n=649)$ [see Table S6 in Additional file 1]. However, there were no differences in baseline characteristics or outcomes between the propensity score-matched patients (Table 4). The mean hemoglobin concentration prior to transfusion was $8.3 \pm$ $1.8 \mathrm{~g} / \mathrm{dl}$ in this subgroup. ICU and in-hospital mortality rates were similar (6.3 vs. $7.3 \%$ and 11.8 vs. $12.2 \%$, respectively, $P>0.2$ pairwise) among transfused and non-transfused-matched pairs.

\section{Subgroup analyses}

The results of univariate and multivariable Cox regression analysis in the a priori defined subgroups are presented in Figure 2. Blood transfusion was associated with a lower risk of in-hospital death in patients aged from 66 to 80 years, in patients admitted to the ICU after non-cardiovascular surgery, in patients with SAPS II score greater than 50 and SOFA score more than four on admission to the ICU, and in patients with severe sepsis.

\section{Discussion}

In this large cohort of surgical ICU patients, hemoglobin concentrations were less than $9 \mathrm{~g} / \mathrm{dl}$ on at least one occasion in $57.6 \%$ of patients. Lower hemoglobin concentrations were associated with higher morbidity and mortality. In a multivariable analysis, higher hemoglobin concentrations and blood transfusions were independently associated with a lower risk of in-hospital death, especially in patients aged from 66 to 80 years, in patients admitted to the ICU after non-cardiovascular surgery, in patients with higher severity scores, and in patients with severe sepsis.

In this study, we demonstrate that anemia is common in surgical intensive care patients. The cause of anemia in 
Table 2: Outcomes according to hemoglobin concentration

\begin{tabular}{|c|c|c|c|c|}
\hline & \multicolumn{2}{|c|}{$\begin{array}{l}\text { Mortality rates } \\
\text { (\%) }\end{array}$} & \multicolumn{2}{|c|}{$\begin{array}{l}\text { Length of stay, days } \\
\text { median (IQR) }\end{array}$} \\
\hline & ICU & Hospital & ICU LOS & Hospital LOS \\
\hline $\begin{array}{l}\text { Admission } \\
\text { hemoglobin } \\
\text { concentration }\end{array}$ & $t$ & $t$ & $\dagger$ & $\dagger$ \\
\hline$<7 \mathrm{~g} / \mathrm{dl}(\mathrm{n}=1109)$ & $120(10.8)$ & $171(15.4)$ & $2(1-5)$ & $12(9-21)$ \\
\hline $7-9 \mathrm{~g} / \mathrm{dl}(\mathrm{n}=1748)$ & $114(6.5)^{*}$ & $196(11.2)^{* *}$ & $2(1-4)$ & $13(10-19)$ \\
\hline $\begin{array}{l}9-11 \mathrm{~g} / \mathrm{dl}(\mathrm{n}= \\
2021)\end{array}$ & $85(4.2)^{*}$ & $158(6.8)^{*}$ & $1(1-3)^{*}$ & $12(9-19)$ \\
\hline $\begin{array}{l}>11 \mathrm{~g} / \mathrm{dl}(\mathrm{n}= \\
1047)\end{array}$ & $42(4.0)^{*}$ & $76(7.3)^{*}$ & $1(1-3)^{*}$ & $11(7-16)^{*}$ \\
\hline $\begin{array}{l}\text { Lowest hemoglobin } \\
\text { concentration }\end{array}$ & $\dagger$ & $\dagger$ & $\dagger$ & $\dagger$ \\
\hline$<7 \mathrm{~g} / \mathrm{dl}(\mathrm{n}=1483)$ & $189(12.7)$ & $259(17.5)$ & $3(1-9)$ & $14(10-25)$ \\
\hline $7-9 \mathrm{~g} / \mathrm{dl}(\mathrm{n}=1928)$ & $104(5.4)^{*}$ & $200(10.4)^{*}$ & $2(1-5)^{*}$ & $13(10-20)^{*}$ \\
\hline $\begin{array}{l}9-11 \mathrm{~g} / \mathrm{dl}(\mathrm{n}= \\
1693)\end{array}$ & $45(2.7)^{*}$ & $99(5.8)^{*}$ & $1(1-2)^{*}$ & $11(8-16)^{*}$ \\
\hline$>11 \mathrm{~g} / \mathrm{dl}(\mathrm{n}=821)$ & $23(2.8)^{*}$ & $43(5.2)^{*}$ & $1(1-1)^{*}$ & $10(7-14)^{*}$ \\
\hline
\end{tabular}

Statistics were performed for columns between categories for initial or minimum hemoglobin concentrations, respectively.

$\dagger P<0.001$ between groups; ${ }^{*}<0.001 \mathrm{vs}<7 \mathrm{~g} / \mathrm{dl} ;{ }^{* *} P<0.05 \mathrm{vs} 7 \mathrm{~g} / \mathrm{dl}$. IQR, interquartile range; LOS, length of stay.

these patients is likely to be multifactorial $[4,21]$. The retrospective design of our study does not allow us to elaborate on the exact cause of the low hemoglobin concentrations. Nevertheless, we found that lower hemoglobin concentrations were associated with poor outcome even after adjustment for possible confounding factors. Our data confirm the results of previous studies in mixed populations of medical and surgical critically ill patients [1,3], in surgical patients who declined blood transfusions [22,23], and in patients with ischemic heart disease $[24,25]$. We additionally demonstrate a correlation between hemoglobin concentrations and organ dysfunction/failure as assessed by the SOFA scores in these patients.

Blood transfusion has also been thought to increase the risk of death in ICU patients [1,3]. Indeed, transfused patients in our study had higher ICU and in-hospital mortality rates; however, after adjustment for possible confounders and severity of illness, blood transfusion was associated with a lower risk of in-hospital death. The discrepancy between our results and those of previous observational studies [1,3] may be related to the implementation of leukoreduction in our institution. Hébert and colleagues [15] reported reduced in-hospital mortality rates after implementation of leukoreduction in a large Canadian multicenter study compared with the control period. van de Watering and colleagues [16] showed increased survival rates in post-cardiac surgery patients transfused with packed RBCs filtered to remove leukocytes compared with those transfused with blood just treated to remove buffy coats. Another possible explanation may be the different case-mix in our study from those of the previous observational cohort studies $[1,3]$, which included mixed medical and surgical ICU patients. Nevertheless, our data support those of the recently published analysis from the SOAP study [2], in which blood transfusion, mostly with leukoreduced blood, was associated with a lower RR of death.

In-hospital mortality was the primary end point in our study. This was also the primary end point for previous prospective randomized [15] and observational studies $[1,3]$. Possible deleterious effects of blood transfusions, especially immunosuppression, are expected to occur later in the course of the disease. The relatively short ICU length of stay in our study may, therefore, render the ICU mortality inadequate in this context.

The results of propensity score matching in our study do not exclude beneficial effects of blood transfusion despite similar outcomes between the matched groups. Severely ill patients were not included in this analysis due to the absence of suitable matched pairs. These patients may be more likely to benefit from blood transfusion, a hypothesis supported by the subgroup analysis in our study. The optimal transfusion trigger in ICU patients has been a matter of controversy. Although randomized controlled trials would be the most appropriate means to 


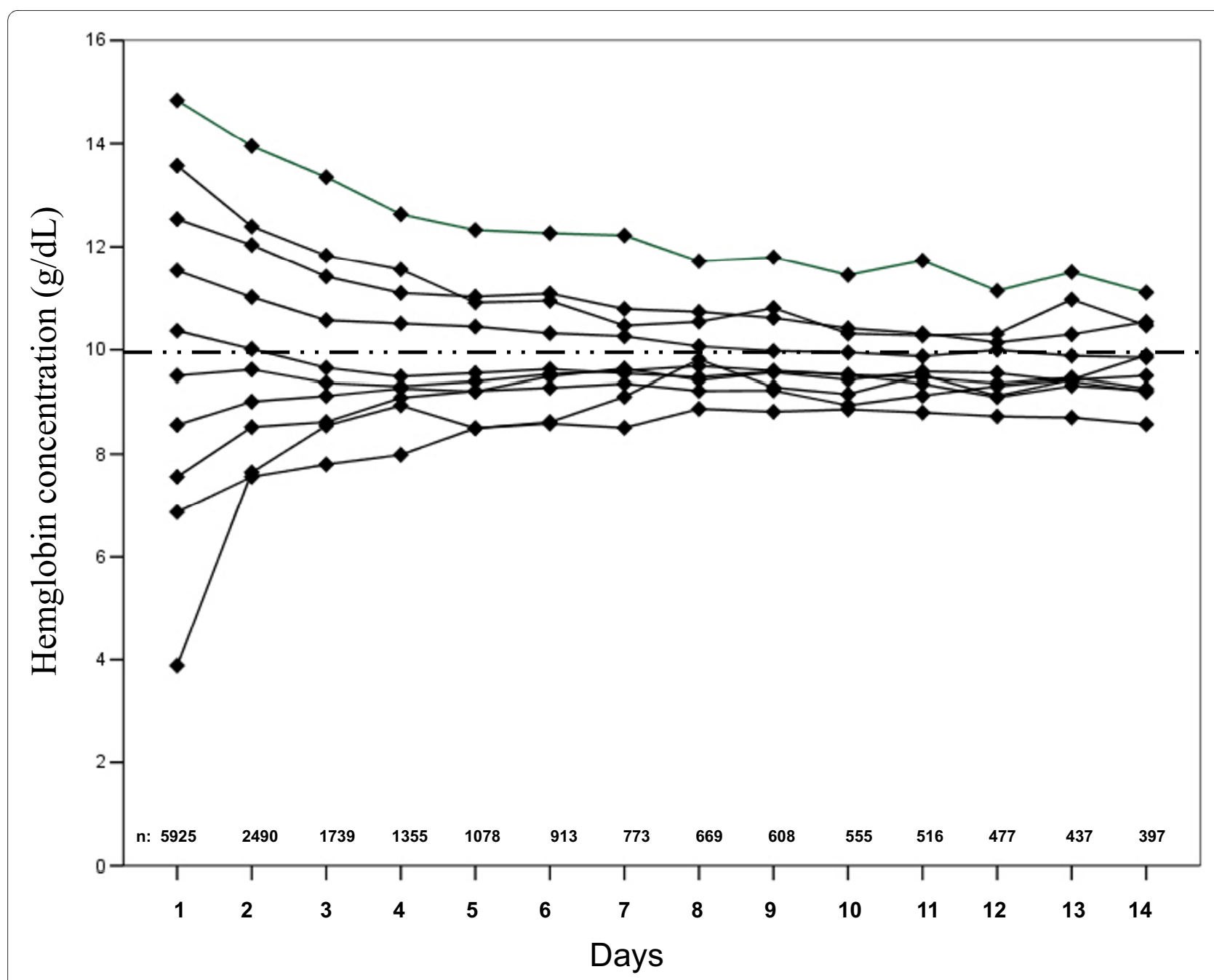

Figure 1 Time course of hemoglobin concentration during the first two weeks in the ICU. This was classified according to hemoglobin concentrations on admission (categories with increments of $1 \mathrm{~g} / \mathrm{dl}$ ). Mean values are displayed.

Table 3: Outcome according to the number of transfused blood units

\begin{tabular}{|c|c|c|c|c|c|}
\hline & $\begin{array}{c}1 \text { unit } \\
(n=381)\end{array}$ & $\begin{array}{c}2 \text { units } \\
(n=683)\end{array}$ & $\begin{array}{l}\text { 3-4 units } \\
(\mathrm{n}=378)\end{array}$ & $\begin{array}{l}5-8 \text { units } \\
(n=224)\end{array}$ & $\begin{array}{l}>8 \text { units } \\
(n=167)\end{array}$ \\
\hline \multicolumn{6}{|l|}{ SOFA scores in the ICU, mean \pm SD } \\
\hline SOFAmax $\dagger$ & $7.5 \pm 3.3$ & $7.9 \pm 3.6^{*}$ & $9.7 \pm 3.4^{*}$ & $12.4 \pm 3.7^{*}$ & $14.9 \pm 3.0^{*}$ \\
\hline SOFAmean $\dagger$ & $6.3 \pm 2.9$ & $6.5 \pm 3.2^{*}$ & $7.5 \pm 3.1^{*}$ & $8.6 \pm 3.6^{*}$ & $9.8 \pm 3.3^{*}$ \\
\hline ICU LOS, days, median (IQR) ‡ & $2(1-5)$ & $3(1-5)^{*}$ & $4(2-9)^{*}$ & $13(6-21)^{*}$ & $28(15-41)^{*}$ \\
\hline Hospital LOS, days, median (IQR) & $14(10-20)$ & $13(10-22)$ & $15(11-25)^{*}$ & $20(13-30)^{*}$ & $34(20-59)^{*}$ \\
\hline Death in ICU (\%) † & $16(4.2 \%)$ & $45(6.6 \%)$ & $37(9.8 \%)^{*}$ & $58(25.9 \%)^{*}$ & $73(43.7 \%)^{*}$ \\
\hline Death in hospital (\%) † & $37(9.7 \%)$ & $88(12.9 \%)$ & $58(15.3 \%)^{*}$ & $69(30.8 \%)^{*}$ & $84(50.3 \%)^{*}$ \\
\hline
\end{tabular}

$+P<0.001$ between groups; $\neq P<0.05$ between groups; ${ }^{*} P<0.001$ vs. patients transfused with one unit of blood. IQR: interquartile range; LOS: length of stay; SD: standard deviation; SOFA: sequential organ failure assessment. 
Table 4: Basic characteristics and outcome among propensity score matched groups

\begin{tabular}{|c|c|c|c|}
\hline & Transfusion & No transfusion & $P$ value \\
\hline $\mathrm{N}$ & 1184 & 1184 & \\
\hline Age, years, mean \pm SD & $64.2 \pm 15.1$ & $64.9 \pm 14.2$ & 0.255 \\
\hline Gender, male (\%) & $717(60.6)$ & $709(59.9)$ & 0.737 \\
\hline \multicolumn{4}{|l|}{ Severity scores on admission mean \pm SD } \\
\hline SAPS II score & $41.8 \pm 16.2$ & $42.2 \pm 17.8$ & 0.370 \\
\hline SOFA score & $7.1 \pm 3.3$ & $7.3 \pm 3.5$ & 0.259 \\
\hline Referring facility & & & 0.694 \\
\hline Operating/recovery room & $914(77.2)$ & $886(74.8)$ & \\
\hline Emergency room & $55(4.6)$ & $88(7.4)$ & \\
\hline Other hospital & $5(0.4)$ & $5(0.4)$ & \\
\hline Other ICU & $101(8.5)$ & $88(7.4)$ & \\
\hline Others & $109(9.2)$ & $117(9.9)$ & \\
\hline \multicolumn{4}{|l|}{ Comorbidities (\%) } \\
\hline Diabetes mellitus & $307(25.9)$ & $327(27.6)$ & 0.353 \\
\hline Chronic renal failure & $187(15.8)$ & $178(15.0)$ & 0.645 \\
\hline Cancer & $181(15.3)$ & $166(14.0)$ & 0.384 \\
\hline Cirrhosis & $28(2.4)$ & $27(2.3)$ & 0.892 \\
\hline COPD & $31(2.6)$ & $34(2.9)$ & 0.706 \\
\hline Heart failure (NYHA III-IV) & $18(1.5)$ & $17(1.4)$ & 0.865 \\
\hline Hematologic cancer & $3(0.3)$ & $2(0.2)$ & 0.654 \\
\hline Surgery within 24 hours (\%) & & & 0.460 \\
\hline Cardiovascular surgery & $563(47.6)$ & $593(50.1)$ & \\
\hline General surgery & $174(14.7)$ & $133(11.2)$ & \\
\hline Neurosurgery & $125(10.6)$ & $141(11.9)$ & \\
\hline Trauma & $94(7.9)$ & $52(4.4)$ & \\
\hline Thoracic surgery & $33(2.8)$ & $33(2.8)$ & \\
\hline Others & $195(16.5)$ & $232(19.6)$ & \\
\hline Unplanned admissions (\%) & $357(30.2)$ & $337(28.5)$ & 0.367 \\
\hline Hemoglobin concentration on admission to the ICU, mean \pm SD & $8.4 \pm 1.9$ & $8.3 \pm 1.7$ & 0.165 \\
\hline Minimum hemoglobin concentration during ICU stay, mean \pm SD & $8.4 \pm 1.9$ & $8.3 \pm 1.7$ & 0.219 \\
\hline \multicolumn{4}{|l|}{ Severity scores, mean \pm SD } \\
\hline SOFAmean & $6.4 \pm 3.0$ & $6.5 \pm 3.3$ & 0.217 \\
\hline SOFAmax & $7.7 \pm 3.5$ & $7.5 \pm 3.6$ & 0.537 \\
\hline ICU mortality rate (\%) & $74(6.3)$ & $87(7.3)$ & 0.289 \\
\hline Hospital mortality rate (\%) & $140(11.8)$ & $144(12.2)$ & 0.800 \\
\hline ICU LOS*, median (IQR) & $1(0-3)$ & $1(1-4)$ & 0.276 \\
\hline Hospital LOS, median (IQR) & $12(9-29)$ & $12(9-17)$ & 0.201 \\
\hline
\end{tabular}

* ICU LOS in patients who did not receive blood transfusion and the time to the first blood transfusion in transfused patients.

COPD: chronic obstructive pulmonary disease; IQR: interquartile range; LOS: length of stay; NYHA: New York Heart Association; SAPS: simplified acute physiology score; SD: standard deviation; SOFA: sequential organ failure assessment. 


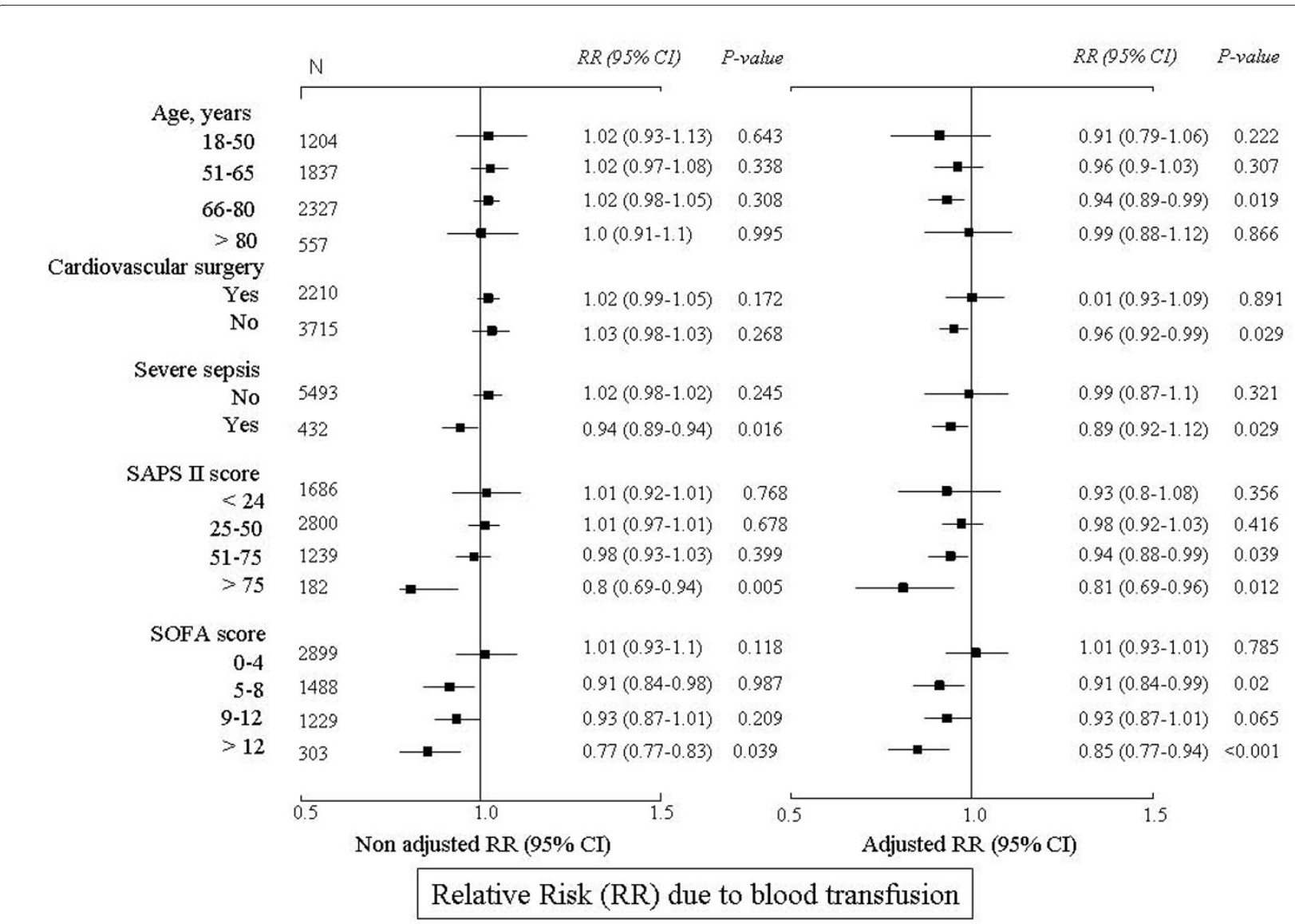

Figure 2 Relative risk of in-hospital death due to blood transfusion in selected subgroups of ICU patients. Left panel demonstrates non-adjusted relative risks (RR). Right panel demonstrates relative risks adjusted to age, gender, comorbidities, severity scores on admission to the ICU, referring facility, type of surgery, the presence of sepsis syndromes, hemoglobin concentration on admission to the ICU, and the number of transfused units of blood. Blood transfusion was introduced in the model as a time-dependent variable in relation to the day on which blood transfusion was carried out. Cl: confidence interval; SAPS: simplified acute physiology score; SOFA: sequential organ failure assessment.

investigate this issue, observational studies such as ours can provide insight, generate hypotheses, and complement the results of randomized studies. Randomized controlled studies in which subjects are randomized to two different therapeutic strategies, independent of their needs, are at risk of therapeutic misassignment [26]. Exclusion of subgroups of patients according to study protocol, dropout of others due to declined consent or non-compliance of physicians, and failure of recruitment are all factors that hinder extrapolation of the results of randomized controlled trials to other patient populations with different case mixes. Changes in practice and quality of care over time may be another important factor that necessitates reassessment of current treatment strategies. Although the TRICC study [9] demonstrated that a restrictive strategy of blood transfusion was as effective as a liberal strategy, leukoreduction was not implemented at the time that study was performed. Whether or not the results of the TRICC study have changed transfusion practice in ICUs is unclear. The mean pre-transfusion hemoglobin concentration in our study was $8.2 \mathrm{~g} / \mathrm{dl}$, which is similar to a large multicenter observational study [3] performed after the results of the TRICC study were published [9] and the evolution of hemoglobin concentrations in our study was also similar to that reported in this study. This could be explained by the limitations of the TRICC study [9] that may hinder the adoption of the restrictive transfusion strategy in all ICU patients.

We also identified subgroups of patients that are more likely to benefit from blood transfusion, including patients with higher severity of illness and more organ dysfunction. These data may help in guiding transfusion practice in surgical ICU patients, until the results of relevant randomized trials are available.

To the best of our knowledge, our study is the largest to date investigating the impact of anemia and possible risks of blood transfusion in surgical intensive care patients. However, some limitations should be considered. First, our analysis is retrospective in nature and our results are only hypothesis generating. A randomized controlled 
trial is warranted to clarify this issue. Second, the multivariable analysis does not take into account unmeasured variables and can not establish a cause-effect relation. The confounding effect of unmeasured variables can not be excluded. Nevertheless, many relevant variables were considered. Third, similar to previous observational [1-3] and interventional studies $[9,10]$, the impact of blood transfusions given before and after the ICU stay on outcome was not evaluated and the indication for blood transfusion was not identified. Fourth, the indication for blood transfusion was not considered in our analysis and may have been an important confounding factor. However, indication for blood transfusion is usually influenced by hemoglobin concentrations, comorbidities, and severity of illness, all of which are factors that were considered in our analysis. Finally, the results of our study may not be extrapolated to patients with other case mixes, such as medical patients.

\section{Conclusions}

In this large cohort of surgical intensive care patients, anemia was common and was associated with higher morbidity and mortality. Higher hemoglobin concentrations and blood transfusions were independently associated with a lower risk of in-hospital death, especially in patients aged from 66 to 80 years, in patients admitted to the ICU after non-cardiovascular surgery, in patients with severe sepsis, and in patients with higher SAPS II and SOFA scores on admission to the ICU. Randomized controlled studies are warranted to confirm the potential benefit of blood transfusion in these subpopulations.

\section{Key messages}

- Anemia is common in surgical ICU patients and is associated with higher morbidity and mortality

- Blood transfusions may be potentially beneficial in patients with higher severity scores, in patients aged from 66 to 80 years, in patients admitted to the ICU after non-cardiovascular surgery, and in patients with severe sepsis

- Our data should be regarded as being hypothesisgenerating and randomized controlled studies are warranted to reassess transfusion practice in the ICU.

\section{Additional material}

Additional file 1 Supplementary material. A word file containing supplementary Tables S1, S2, S3, S4, S5 and S6 and Figures S1, S2 and S3.

\section{Abbreviations}

APACHE: acute physiology and chronic health evaluation; IQR: interquartile RBC: red blood cell; RR: relative risk; SAPS: simplified acute physiology score; SOAP: sepsis occurrence in acutely ill patients; SOFA: sequential organ failure assessment; TRICC: transfusion requirements in critically ill patients; TRIM: transfusion-related immunosuppression;

\section{Competing interests}

The authors declare that they have no competing interests.

\section{Authors' contributions}

All authors participated in the design of the study. YS, SL, and SK contributed to data collection. YS analyzed the data. YS and SL drafted the manuscript. EE, MB, US, DB, and KR revised the article. All authors read and approved the final manuscript.

\section{Author Details}

1 Department of Anesthesiology and Intensive Care, Friedrich Schiller University Hospital, Erlanger Allee 103, Jena, 07743, Germany, 2Department of General and Vascular Surgery, Friedrich Schiller University Hospital, Erlanger Allee 103, Jena, 07743, Germany and ${ }^{3}$ Institution of Transfusion Medicine, Friedrich Schiller University Hospital, Erlanger Allee 103, Jena, 07743, Germany

Received: 26 December 2009 Revised: 14 March 2010

Accepted: 24 May 2010 Published: 24 May 2010

References

1. Vincent JL, Baron JF, Reinhart K, Gattinoni L, Thijs L, Webb A, MeierHellmann A, Nollet G, Peres-Bota D, ABC (Anemia and Blood Transfusion in Critical Care) Investigators: Anemia and blood transfusion in critically ill patients. JAMA 2002, 288:1499-1507.

2. Vincent JL, Sakr Y, Sprung C, Harboe S, Damas P: Are blood transfusions associated with greater mortality rates? Results of the Sepsis Occurrence in Acutely III Patients study. Anesthesiology 2008, 108:31-39.

3. Corwin HL, Gettinger A, Pearl RG, Fink MP, Levy MM, Abraham E, Macintyre NR, Shabot MM, Duh MS, Shapiro MJ: The CRIT Study: Anemia and blood transfusion in the critically ill--current clinical practice in the United States. Crit Care Med 2004, 32:39-52.

4. Vincent $J \mathrm{~L}, \mathrm{Sak} r \mathrm{Y}, \mathrm{Creteur} J$ : Anemia in the intensive care unit. Can J Anaesth 2003, 50:S53-S59.

5. Malone DL, Dunne J, Tracy JK, Putnam AT, Scalea TM, Napolitano LM Blood transfusion, independent of shock severity, is associated with worse outcome in trauma. J Trauma 2003, 54:898-905.

6. Palmieri TL, Caruso DM, Foster KN, Cairns BA, Peck MD, Gamelli RL, Mozingo DW, Kagan RJ, Wahl W, Kemalyan NA, Fish JS, Gomez M, Sheridan RL, Faucher LD, Latenser BA, Gibran NS, Klein RL, Solem LD, Saffle JR, Morris SE, Jeng JC, Voigt D, Howard PA, Molitor F, Greenhalgh DG, American Burn Association Burn Multicenter Trials Group: Effect of blood transfusion on outcome after major burn injury: a multicenter study. Crit Care Med 2006, 34:1602-1607.

7. Koch CG, Li L, Duncan Al, Mihaljevic T, Cosgrove DM, Loop FD, Starr NJ, Blackstone $\mathrm{EH}$ : Morbidity and mortality risk associated with red blood cell and blood-component transfusion in isolated coronary artery bypass grafting. Crit Care Med 2006, 34:1608-1616.

8. Rao SV, Jollis JG, Harrington RA, Granger CB, Newby LK, Armstrong PW, Moliterno DJ, Lindblad L, Pieper K, Topol EJ, Stamler JS, Califf RM: Relationship of blood transfusion and clinical outcomes in patients with acute coronary syndromes. JAMA 2004, 292:1555-1562.

9. Hébert PC, Wells G, Blajchman MA, Marshall J, Martin C, Pagliarello G, Tweeddale M, Schweitzer I, Yetisir E: A multicenter, randomized, controlled clinical trial of transfusion requirements in critical care. Transfusion Requirements in Critical Care Investigators, Canadian Critical Care Trials Group. N Engl J Med 1999, 340:409-417.

10. Lacroix J, Hébert PC, Hutchison JS, Hume HA, Tucci M, Ducruet T, Gauvin F, Collet JP, Toledano BJ, Robillard P, Joffe A, Biarent D, Meert K, Peters MJ, TRIPICU Investigators, Canadian Critical Care Trials Group, Pediatric Acute Lung Injury and Sepsis Investigators Network: Transfusion strategies for patients in pediatric intensive care units. N Engl J Med 2007 356:1609-1619.

11. Schreiber GB, Busch MP, Kleinman SH, Korelitz JJ: The risk of transfusiontransmitted viral infections. The Retrovirus Epidemiology Donor Study. NEngl J Med 1996, 334:1685-1690.

12. Shapiro MJ: To filter blood or universal leukoreduction: what is the answer? Crit Care 2004, 8(Suppl 2):S27-S30.

13. Blumberg N, Heal JM: Immunomodulation by blood transfusion: an evolving scientific and clinical challenge. Am J Med 1996, 101:299-308.

14. Vamvakas EC, Blajchman MA: Transfusion-related immunomodulation (TRIM): an update. Blood Rev 2007, 21:327-348. 
15. Hébert PC, Fergusson D, Blajchman MA, Wells GA, Kmetic A, Coyle D,

Heddle N, Germain M, Goldman M, Toye B, Schweitzer I, vanWalraven C, Devine D, Sher GD, Leukoreduction Study Investigators: Clinical outcomes following institution of the Canadian universal leukoreduction program for red blood cell transfusions. JAMA 2003 , 289:1941-1949.

16. van de Watering LM, Hermans J, Houbiers JG, van den Broek PJ, Bouter $H$, Boer F, Harvey MS, Huysmans HA, Brand A: Beneficial effects of leukocyte depletion of transfused blood on postoperative complications in patients undergoing cardiac surgery: a randomized clinical trial. Circulation 1998, 97:562-568.

17. Le Gall JR, Lemeshow S, Saulnier F: A new Simplified Acute Physiology Score (SAPS II) based on a European/North American multicenter study. JAMA 1993, 270:2957-2963.

18. Vincent JL, Moreno R, Takala J, Willatts S, De Mendonça A, Bruining H, Reinhart CK, Suter PM, Thiijs LG: The SOFA (Sepsis-related Organ Failure Assessment) score to describe organ dysfunction/failure. On behalf of the Working Group on Sepsis-Related Problems of the European Society of Intensive Care Medicine. Intensive Care Med 1996, 22:707-710.

19. American College of Chest Physicians/Society of Critical Care Medicine Consensus Conference: definitions for sepsis and organ failure and guidelines for the use of innovative therapies in sepsis. Crit Care Med 1992, 20:864-874

20. Rubin DB: Estimating causal effects from large data sets using propensity scores. Ann Intern Med 1997, 127:757-763.

21. Sihler KC, Napolitano LM: Anemia of inflammation in critically ill patients. J Intensive Care Med 2008, 23:295-302.

22. Carson JL, Duff A, Poses RM, Berlin JA, Spence RK, Trout R, Noveck H, Strom BL: Effect of anaemia and cardiovascular disease on surgical mortality and morbidity. Lancet 1996, 348:1055-1060.

23. Carson JL, Noveck H, Berlin JA, Gould SA: Mortality and morbidity in patients with very low postoperative $\mathrm{Hb}$ levels who decline blood transfusion. Transfusion 2002, 42:812-818

24. Wu WC, Rathore SS, Wang Y, Radford MJ, Krumholz HM: Blood transfusion in elderly patients with acute myocardial infarction. NEngl J Med 2001, 345:1230-1236.

25. Sabatine MS, Morrow DA, Giugliano RP, Burton PB, Murphy SA, McCabe $\mathrm{CH}$, Gibson CM, Braunwald E: Association of hemoglobin levels with clinical outcomes in acute coronary syndromes. Circulation 2005, 111:2042-2049.

26. Deans KJ, Minneci PC, Suffredini AF, Danner RL, Hoffman WD, Ciu X, Klein HG, Schechter AN, Banks SM, Eichacker PQ, Natanson C: Randomization in clinical trials of titrated therapies: unintended consequences of using fixed treatment protocols. Crit Care Med 2007, 35:1509-1516.

doi: $10.1186 /$ cc9026

Cite this article as: Sakr et al., Anemia and blood transfusion in a surgical intensive care unit Critical Care 2010, 14:R92

Submit your next manuscript to BioMed Centra and take full advantage of:

- Convenient online submission

- Thorough peer review

- No space constraints or color figure charges

- Immediate publication on acceptance

- Inclusion in PubMed, CAS, Scopus and Google Scholar

- Research which is freely available for redistribution

Submit your manuscript at www.biomedcentral.com/submit
C Biomed Central 